case of need, I do not feel justified in recommending operation, unless examination reveals any incipient failing on the part of the eye to hold its own.

The number of recorded cases, with late results, many of, which concern eyes that have been trephined up to six years, "is 96 .

As to final results :-

Acute Glaucoma. Improved $\quad \ldots \quad \ldots \quad=70$ per cent.

$$
\text { Stationary } \quad \cdots \quad \cdots \quad=25 \quad,
$$

Worse $\quad \cdots \quad \cdots=5 \quad$ "

Sub-acute Glaucoma. Improved $\quad \ldots=47$ ",

Stationary $\quad \cdots=42 \quad$,

$\begin{array}{rllll}\text { Simple Chronic Glaucoma. Improved } & \ldots & =32 & = & \\ \text { Stationary } & \ldots & =48 & , \\ \text { Worse } & \ldots & =20 & \end{array}$

These figures refer to visual acuity.

With regard to the chronic form, those that were worse were due to (1) recurrence of the disease requiring further operative treatment; (2) the quiet iritis which used to be found before the days when I instilled strong atropin solution at the end of the operation; (3) opacification of the lens, not the result of trauma at the operation.

The best one can expect in most cases of simple chronic glaucoma is to retain the vision which remains at the time of the operation, and if 80 per cent. is the true proportion, it is far superior to the 62 per cent. claimed for iridectomy,* and I consider in the future with the experience already gained, the percentage of retention of vision, as good as before the operation, will be even greater. I! bi

I wish to express my obligation to Dr. Lily Stopford for valuable assistance in the preparation of this paper.

\title{
A CASE OF LEUCO-SARCOMA OF THE CHOROID WITH EPITHELIOMA OF THE LIP IN THE SAME PATIENT $\dagger$
}

BY

J. A. Valentine, M.D.

Elizabeth Bailey, aged 55, epithelioma of lip removed, with glands of neck, on the right side, in October, 1915, at the Portsmouth Royal Hospital.

"Trans. Ophthal. Soc., U.K., Vol. XXII, 1902, p. 5.

$\dagger$ Read at the 1917 meeting of the Ophthalmological Society of the United Kingdom. The full communication will be published in the Society's Transactions. 
More than a year later, in October, 1916, she came to the Eye and Ear Hospital, Portsmouth, complaining of loss of vision in the left eye.

On examination.-Right vision $=$ fingers at 1 metre; the lens was cataractous; the fundus showed a myopic crescent. The left eye had vision 6/36; media clear; conjunctiva, cornea, anterior chamber and iris appeared normal. There was a large limitation of field on the temporal side, when tested roughly by the hand, and she complained of seeing "lights" to the same side.

On examining the fundus, a rounded tumour was seen towards the nasal side, which almost reached the margin of the disc. It appeared to be a sarcoma, but was lighter in colour than the usual appearance of choroidal sarcoma. Small vessels could be seen bending round the curve of the tumour.

The tumour eye was excised on Nov. 14, 1916. Vertical diameter of section of tumour, $10 \mathrm{~mm}$. Antero-posterior diameter, $9 \mathrm{~mm}$. Colour white, like a section of nerve. A section was made of the tumour by a Research Society, which reported it to be a glioma of the retina. That did not satisfy me. I therefore submitted the section to Mr. R. Affleck Greeves, who kindly made the following report on it:

Describtion of a microscopical section, taken across the posterior part of the eyeball at the level of the obtic nerve.

"A large nodule of growth is seen-this is evidently the projecting part of a mushroom-shaped mass, which has been cut across beyond the level of the place of origin of the main mass from the choroid.

A double layer of retina surrounds the nodule, showing that a considerable detachment was present. The growth is undoubtedly choroidal in origin, and consists of a mass of cells which show no sign of any special mode of arrangement. Fine layers of fibrous stroma traverse the mass. Numerous blood-vessels are presentthese consist of cleft-like spaces, each lined by a single layer of endothelium. The cells' which make up the growth are for the most part of moderate size-they contain well-marked nuclei, which stain deeply with hæmatoxylin, and enclose distinct nucleoli-the latter are frequently two in number in a single nucleus. Both round cells and spindle cells are present-their relative proportions vary in different parts of the growth. No pigment is to be found in any part which appears in the section.

The growth is a fairly typical leuco-sarcoma of the choroid."

.The occurrence of two different types of malignant disease in the same patient within about a year, is, I think, unusual ; either growth, unless removed in time, would have had a fatal result, but so far, the patient still enjoys good health. I do not think there is any connection between the epithelioma of the lip and the sarcoma of 
the choroid, except the mere coincidence of their occurrence in the same patient.

No relative of hers that she knows of has had any kind of growth, or has been operated on for a tumour in the eye or elsewhere.

\title{
CIRCUMOCULAR FILARIASIS *
}

\author{
BY \\ E. J. Stuckey, M.B., B.Sc.,
union medical college, peKing.
}

ON January 10, 1916, a Chinese named Jung, aged 25 years, yamen servant by occupation, came to the Eye Clinic of the Union Medical College Hospital, and stated that since the preceding summer there had seemed to be a "worm " or "worms" in his right eye.

A careful examination failed to disclose anything abnormal and I was prepared to ridicule his statement as on a par with the frequent ascription of trouble in any part of the body to "worms" in that region. However, the patient produced a bottle with a small object like a piece of white thread in it which he said he had removed from his eye two days before.

A very careful examination in the upper fornix revealed a moving body almost invisible against the conjunctiva.

After the eye had been cocainized, four white worms, like threadworms, 8-13 $\mathrm{mm}$. long, were removed from the fornices. None was discovered in the left eye.

On January 12, 1916, patient returned with the statement that on the previous day he had removed another worm from his right eye. On further investigation no more worms were to be seen.

Unfortunately, the man was allowed to go away without an examination of the fæces for the presence of parasites.

By a coincidence my wife had been at Tungchow a short time prior to this incident, and the Rev. T. Biggin, Professor of Biology in Tungchow Arts College, had told her that worms had been removed from the eyes of his pet dog. Mr. Biggin had preserved specimens of these worms, and kindly lent them for comparison with those from this patient. These parasites have been forwarded for identification to Dr. Henry S. Houghton, of the Harvard Medical School, Shanghai.

*Reprinted from the China Medical Journal, January, 1917. 